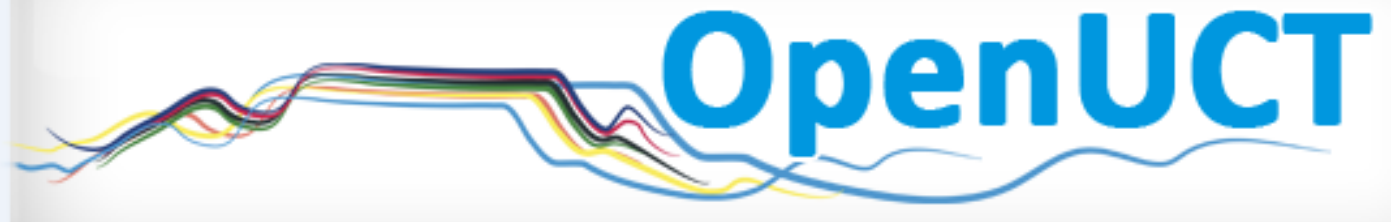

This is the post-print of Allie, S., Armien, M. N., Burgoyne, N., Case, J. M., Collier-Reed, B. I., Craig, T. S., Deacon, A., Fraser, D. M. et al. 2009. Learning as acquiring a discursive identity through participation in a community: improving student learning in engineering education.

European Journal of Engineering Education. 34(4): 359-367. DOI: 10.1080/03043790902989457.

It is made available according to the terms of agreement between the author and the journal, and in accordance with UCT's open access policy available:

http://www.openuct.uct.ac.za/sites/default/files/UCTOpenAccessPolicy.pdf, for the purposes of research, teaching and private study. 


\title{
Learning as acquiring a discursive identity through participation in a community: improving student learning in engineering education
}

Saalih Allie ${ }^{\mathrm{a}}$, Mogamat Noor Armien ${ }^{\mathrm{b}}$, Nicolette Burgoyne ${ }^{\mathrm{a}}$, Jennifer M. Case ${ }^{\mathrm{a}}$, Brandon I. Collier-Reed ${ }^{a}$, Tracy S. Craig ${ }^{a}$, Andrew Deacon ${ }^{a}$, Duncan M. Fraser ${ }^{a}$, Zulpha Geyer $^{a}$, Cecilia Jacobs $^{\mathrm{b}}$, Jeff Jawitz ${ }^{\mathrm{a}}$, Bruce Kloot ${ }^{\mathrm{a}}$, Linda Kotta ${ }^{\mathrm{a}}$, Genevieve Langdon ${ }^{\mathrm{a}}$, Kate le Roux ${ }^{\mathrm{a}}$, Delia Marshall $^{c}$, Disaapele Mogashana ${ }^{a}$, Corrinne Shaw ${ }^{a}$, Gillian Sheridan ${ }^{a}$ and Nicolette Wolmarans ${ }^{a}$

${ }^{a}$ Centre for Research in Engineering Education, University of Cape Town, Private Bag, Rondebosch 7701, South Africa

${ }^{\mathrm{b}}$ Department of Civil Engineering, Cape Peninsula University of Technology

${ }^{c}$ Department of Physics, University of the Western Cape

\begin{abstract}
In this paper, we propose that learning in engineering involves taking on the discourse of an engineering community, which is intimately bound up with the identity of being a member of that community. This leads to the notion of discursive identity, which emphasises that students' identities are constituted through engaging in discourse. This view of learning implies that success in engineering studies needs to be defined with particular reference to the sorts of identities that students develop and how these relate to identities in the world of work. In order to achieve successful learning in engineering, we need to recognise the multiple identities held by our students, provide an authentic range of engineering-related activities through which students can develop engineering identities and make more explicit key aspects of the discourse of engineering of which lecturers are tacitly aware. We include three vignettes to illustrate how some of the authors of this paper (from across three different institutions) have applied this perspective of learning in their teaching practice.
\end{abstract}

Keywords: engineering education; student learning; discourse; identity; participation

\section{Introduction}

Worldwide there has been an increasing demand for engineers, without a concomitant increase in the output of new engineering graduates. There has also been an increasing concern with the quality of engineering programmes, as signified by greater desire of countries to be part of the accords that mutually recognise each other's qualifications (Hanrahan 2008).

There have been a number of waves of engineering education reform, both in the developed world and the developing world. In the 1990s, there was a strong emphasis on improving teaching and learning, as well as the introduction of engineering courses in the first year of university study 
(see, for example, Ambrose and Amon 1997, Hoit and Ohland 1998). The latest wave has involved re-focusing accreditation from being content driven to being outcome based (Jawitz et al. 2001).

The engineering community in South Africa has been closely involved in these changes. Our history of segregated schooling has left us with particularly strong challenges associated with the diversity in our classes, with many students having been poorly prepared for the demands of tertiary engineering education. Recently, the situation has been exacerbated by the increasing need for engineers locally, coupled with a decline in the quality of student intake (Lawless 2005).

We would argue that many of the current responses to these educational challenges seem to rest on anecdotal wisdom, or at best on a set of pedagogical theories that are not necessarily well suited to the understanding of the situation at hand. We need to develop a deeper understanding of the systems we work in, for with better ways of understanding student learning, we will be better equipped to develop context-sensitive and effective ways of providing occasions for effective learning to take place. In this paper, we present a perspective of learning that we find useful in conceptualising our work as engineering educators. This perspective views learning in engineering as a process of coming to participate in the discourse of the engineering community and taking on the identity of being a member of this community. We use three teaching and learning vignettes from South African classrooms to illustrate what the adoption of such a perspective might look like in practice.

\section{A participation view of learning}

Drawing on Sfard's (1998) mapping of the landscape of possible theories, we find it useful to locate the range of possible theories of learning on a continuum, based on an increasing awareness of the social dimensions of learning. On the one side of the continuum are those using the acquisition perspective, and on the other are those using a participation perspective.

The acquisition perspective, a perspective that has dominated educational thinking in recent decades, views learning as the acquisition of something, usually termed 'knowledge', suggesting that learning has some endpoint. The participation perspective, a view that is less commonly used, but rapidly gaining importance, views learning as an ongoing process of participation, of becoming a member of a community, and therefore of developing a particular identity within that community (Brown et al. 1989, Lave and Wenger 1991). From this perspective, the goal of learning is being able to act in a particular environment, where 'acting' is defined as being able to use the specialist discourse of that community. Since learning is defined as an ongoing process, it is not possible to view learning as participation without explicit consideration of the educational context in which the learning takes place, for example, the background of the students, the communities that students already belong to or have belonged to in the recent past, and the workplace community in which the successful student will need to function.

At this point, it is important to clarify what we mean when we use the word 'community' in the context of engineering. We are not claiming that undergraduate students can be full members of the workplace communities of engineers. However, through participation in classroom activities they are working towards ultimate membership of these communities (cf. Dahlgren et al.2006). These classroom activities, we would argue, need to bear some relation to the authentic activities in which the students will ultimately engage. For example, a recent study (Jonassen et al. 2006) suggests that workplace engineering problems tend to be poorly structured and ill-defined, and require that engineers work collaboratively, sometimes with people outside the community of engineers. Many aspects of our curricula already reflect the goal to provide authentic activities, in that we have engineering students engaging in practical and design activities. What the participation perspective suggests is that these should be seen as central learning activities in our degree programmes. Furthermore, such activities need to be productive in the sense that they 
enable meaningful participation. Case et al. (2002) investigated whether engineering students experienced 'legitimate peripheral participation' when engaged in industrial vacation work; they found that access to meaningful activity is a central determinant of whether the students have a productive learning experience or not, and they noted the important role of the mentoring engineer in advocating for the student's status as a legitimate participant in the workplace.

Given the relative predominance of the acquisition perspective in much existing engineering education literature, we have chosen rather to explore the implications for our practice of adopting the participation perspective. However, following Sfard (1998), it is important to point out that we are certainly not saying that this is the only valid view of teaching and learning. First, we acknowledge that research conducted from the acquisition perspective has made valuable contributions to our current knowledge of engineering education; for example, the awareness we now have of the impact of learners' prior knowledge on teaching and learning situations (Ausubel 1968). Second, we acknowledge the complex nature of teaching and learning (Brown 2000), and since our theories of learning impact on our practice, we would argue that the wider the range of useful perspectives that we have, the more successful we will be in our teaching.

\section{Discursive identity}

In characterising the forms of participation relevant to engineering education, we have found the concept of discourse useful (Gee 2001). We use the term discourse to refer to certain ways of using language, acting, interacting, behaving, believing, using tools, sign systems, and so forth, which characterise a particular community. For example, the discourse of being an engineer will involve the practice of design to solve real-world problems, and this includes collecting and analysing data, using empirical laws and correlations, doing mathematical calculations and modelling, as well as presenting one's results to a range of different audiences. Through our use of the characteristics of a discourse, we can recognise ourselves and others as belonging to the community. The notion of identity is thus central, for being in a discourse community implies taking on an identity as a member of that community. Gee characterises identity as "the "kind of person" one is recognised as "being", at a given time and place' (Gee 2001, p. 99). This view of identity does not focus on internal psychological makeup but is about how you present yourself to the world and how the world recognises you. Since one can be a member of multiple communities, one can hold multiple identities.

Because of the centrality of discourse to our notion of identity, we use the term discursive identity (Brown et al. 2005) to emphasise that students' identities are constituted through discourse. Discursive identity 'reflects an understanding that speakers select genres of discourse with the knowledge (tacit or implicit) that others will ... interpret their discourse as a signal of their cultural membership' (Brown et al. 2005, p. 783). Acknowledging students' agency to choose identities, students are seen to use discourse with the full awareness that others will use this as an indication of their membership of particular communities. These new identities will involve crossing 'boundaries' from the identities that they already hold, but as stated above students are able to maintain multiple identities. This is very different to simply 'acquiring knowledge'; engaging with engineering is an act that has implications for how others will see you.

The classroom community is clearly an important resource in providing a safe space where students can start to experiment with new identities. Sitting passively in a lecture hall gives limited opportunities for developing your identity, and that is why we need to include in our programmes many more opportunities to discuss technical problems with peers, to present one's findings, and sometimes even just to engage socially with other engineering students. Where students find that they are unable to reconcile their existing identities with the new engineering identity being explored in the programme one can expect that poor academic performance might follow. 
Otherwise this 'identity crisis' manifests in later career choices where a student might choose not to join the community of engineers, but rather work in other sectors of the economy.

Having described our theoretical position, we now illustrate the utility of this theoretical position focusing on learning as the development of discursive identity. First, we look at the world of work and use this theory to reconsider the learning outcomes towards which engineering education should aim. Then we look to the world of the learner, and consider the identities that students bring with them to the education environment. Finally, we look inwards to the classroom to suggest how we might promote more effective learning through the development of discursive identity.

\section{What constitutes success in engineering studies?}

In our understanding, success is the demonstration of the ability to use the relevant discourse to be able to participate in a workplace community. Clearly the classroom community can never be identical to the workplace community. However, the classroom community should provide a realistic representation of the range of identities in the workplace that students could productively adopt as engineers. Arguably many engineering programmes have a strong history of industry links and these continue to play an important role in how programmes are designed and accredited, but there remains a question of to what extent the learning experience reflects the dynamic and diverse world of work. Graduates with engineering degrees work in an extremely wide range of technical contexts, including manufacturing industries, research organisations, environmental and social organisations, the financial sector, and government departments. Yet Johnston et al. (1996) argue that engineering education has been dominated by the discourse of engineering science, to the relative neglect of other discourses, which play important roles in the engineering workplace, including ethics, management, commerce, politics, sociology, environmental science, and so on. A particular challenge for the engineering profession is that there is limited display of their workplace identities in the popular media, compared to professions like law or medicine (even though television shows may give a somewhat distorted view on life in the workplace). We would argue that programmes in many higher education institutions seem to represent a relatively narrow set of discursive identities, primarily research and academic identities.

\section{What identities do learners bring with them?}

In defining what we regard as success in engineering education, we have focused on the communities into which graduates might move. However, in order to promote success, we need to develop an understanding of the communities from which students come. Students come from a diverse set of backgrounds, and therefore bring with them a range of identities. They are not robots that can be plugged into programmes; they have aspirations and display agency in terms of selecting discursive identities that are congruent with those that they already carry.

There are a variety of reasons why students enter engineering. We are aware that for some students in South Africa, concern for addressing social issues such as the desire to improve the quality of life in their home communities is a major reason for enrolling in engineering studies (Jawitz and Case 1998). There is a question as to whether such students are given the opportunity to take on discursive identities that embody these concerns. Students seldom have the space to make these aspirations explicit within the learning environment, and these identities are unlikely to be developed if they are not part of the formal goals of the programme.

The engineering education literature contains a number of key studies, which use a focus on identity to explore the impact of gender on engineering students' experiences (for example, 
Stonyer 2001, Walker 2001, Phipps 2002, Tate and Linn 2005). Walker (2001) argues that the engineering identities taken on by the students in her study 'both challenge and leave dominant gender relations in place' (p. 86). She found that women engineering students tended to adopt a 'resistance' identity in which they asserted their difference from other females, and 'claimed to be "more like the boys" ' (p. 81). These identities offered a way of succeeding in engineering education, but they did not challenge the dominant gender relations and resulted in the women being cast in stereotyped roles that they did not welcome, for example, as organised and hard working. Furthermore, for male students who did not identify with the views of maleness that predominated, there was also little room to move. Thus, the dominant culture ended up as a disadvantage to a subset of both women and men.

\section{How might we achieve successful learning?}

How might we promote the development of a successful discursive identity in engineering? To answer this question we need to go a bit deeper into understanding the nature of the discourse. Engineering (like science) is a human social activity conducted within cultural and institutional frameworks (Lemke 2001). Learning to use a discourse implies some community where this new discourse can be exercised and developed. As established earlier, to use a discourse is to own an identity, and to do so successfully means that you will be recognised as a competent member of a particular community. In order to learn authentically and participate in a community, a student must master the discourse of this community, becoming fluent in the social practices through which meaning is made. In the context of engineering education, being a competent member of a community means one is competent in the particular ways of reading, writing, speaking, using symbolic systems including mathematics and modelling, using tools, behaving, interacting, believing, displaying a particular world view, etc. that are considered appropriate by that discourse community. We describe someone who can use a discourse proficiently as 'literate', and it is important to recognise here that this is a broad definition of being literate, not simply referring to the mastery of the relevant grammar and vocabulary.

In starting to develop an approach to teaching that focuses on the development of discourse, we have drawn on research in the field of 'academic literacies' (Lea and Street 2006). Developing 'academic literacies' cannot be achieved by an add-on course, but must be infused into all aspects of the educational experience. For example, learning the discourse of engineering is central to learning engineering and, therefore, it is in the core 'engineering' courses that the responsibility for developing academic literacies needs to reside.

Teaching in this way is a challenge. The key aspects of a discourse are often taken for granted by those who practise the discourse and are seldom made explicit to students. We argue that lecturers need to focus on making what is tacit in a particular discourse explicit. For those who are fully immersed in the discourse, it can be very difficult to 'make the tacit explicit' (Jacobs 2007). One strategy is to work collaboratively with other lecturers, both in and out of the field. Specific recommendations point towards making the generic structures and discourse patterns in texts clearer for students, and making explicit for students the rhetorical patterns underpinning their disciplinary knowledge bases. This links strongly with our earlier argument for the need for closer links to the authentic world of work, since engagement with the practice of engineering can help elaborate how these workplace communities 'read' and 'write' themselves, use symbolic systems and tools, act, and so on.

In order to illustrate how it is possible to implement this participative view of student learning, the following section presents three vignettes of how some of the authors of this paper have, in their own disciplinary contexts, made changes to their practice to enact these ideas. 


\section{A participative view of student learning in practice}

Within the Faculty of Engineering at her institution, Jacobs has focused on what the development of discursive identities in students might mean for the lecturers who teach them (Jacobs 2007).

She actively worked towards improving how lecturers could bring the tacit knowledge and understandings they have of the workings of discourses within their disciplines, into the domain of overt and explicit teaching. Part of the approach she adopted was to establish collaborative partnerships between academic development practitioners and engineering lecturers. This provided spaces where lecturers could explore their roles and identities as discourse teachers and expand their disciplinary identities to include that of a discourse teacher. This process took place during joint planning sessions between the lecturers and academic development practitioners. In these planning sessions they collaboratively prepared teaching materials aimed at making the discourses of engineering explicit to their students, with a view to implementing these teaching materials in lessons that were team-taught by both the lecturers and academic development practitioners. These joint planning sessions brought about a deeper awareness, especially among the lecturers, of the workings of discourse within their disciplines. The engineering lecturers ascribed this to the fact that their academic development practitioner partners were 'outsiders' to their disciplinary discourse communities, and therefore able to shift the 'insider' lecturers out of their disciplinary communities and allow them to view it from the outside, as a novice student would. This awareness was in turn applied to the classroom practices of the participants in a variety of ways, including peer classroom observation, collaborative materials development, and team teaching.

The first classroom practice that assisted in bringing about an explicit awareness of disciplinary discourses was that of peer classroom observation between engineering lecturers and academic development practitioners. This process was particularly valuable to the academic development practitioners who were able to 'see' the classroom disciplinary discourses in action, and then reflect this back to the engineering lecturers. The second practice that assisted in bringing about an explicit awareness of disciplinary discourses was that of the collaborative development of classroom materials. One of the ways in which the collaborating lecturers attempted to make disciplinary discourses explicit was to develop materials that interrogated not only the words, symbols, diagrams, and formulas through which their disciplines communicated meaning, but also the actions and practices underpinning these expressions of discourse. In working with written texts from their disciplines, lecturers developed materials that encouraged students to interrogate the complex relationships between the author of a text and the intended audience, as well as the broader social context within which such a text operated. Other strategies involved making the generic structures and discourse patterns in texts clearer for students and engaging students in writing for an authentic purpose that was linked to a tangible audience (other than the lecturer).

The third classroom practice that assisted in bringing about an explicit awareness of disciplinary discourses was that of team teaching between engineering lecturers and academic development practitioners, which provided the collaborative partnerships with a context of practice, within which they could explore different teaching approaches to making disciplinary discourses explicit. Where partnerships were open to a discursive approach to team teaching, the participants seemed to find synergies between their respective approaches to teaching and learning. One partnership saw their team teaching as a conversation, while another partnership saw their team teaching as a relay. The experience of jointly planning lessons and then collaboratively teaching them brought the methodological implications of being a discourse teacher to the fore. The lecturers viewed this experience as particularly helpful in trying to understand what the explicit teaching of disciplinary discourses meant in practice.

In a nearby institution, Marshall and her colleagues in the Department of Physics faced a similar challenge when they recognised that the discourse in their discipline was often taken for granted as 'transparent' by lecturers (Holtman and Marshall 2008). Since the knowledge of a disciplinary 
discourse has a tacit dimension, it was often difficult for the lecturers (who, as above, were essentially 'insiders') to make this knowledge explicit to their students. A collaborative partnership in their introductory physics course was established, with the lecturers (the insiders) working closely with an academic development practitioner (an outsider, who as in the vignette above was able to identify with the difficulties that the students faced) in the design and teaching of the course. The process of making the tacit explicit took several forms. For example, learning activities made explicit the different verbal, pictorial, physical, graphical and mathematical representations that comprise the disciplinary discourse of physics. There was also an explicit focus on the conceptual and representational aspects of problem-solving, and a focus on the nature of science ran as a thread throughout the physics content during the year. The team placed explicit focus on learning as identity formation through participation in a community. For example, the traditional lectures were replaced by workshop-style classes in which students worked in co-operative learning groups, so that students had opportunities to discuss and talk about the discipline. A further dimension of the course was that the practicals were set up to be quasi-authentic and investigation-based with enough time allocated so that the students could explore and make explicit those aspects of doing practicals that are often taken for granted. Another aspect introduced was to emphasise to students that there was not one sole identity as a 'physicist' (usually the academic/researcher identity) by exposing them to a range of work place identities. This was done by inviting speakers who were all using physics in different ways in their careers (e.g. an astronomer, nuclear risk analyst, industrial geo-physicist). Finally, the course foregrounded the social, political, environmental, and ethical dimensions of the discipline in general.

At a third institution, Case et al. (2007) redeveloped a first-year introductory course in chemical engineering along the line of argument in this paper. Central to their approach was to focus on students' need to be actively involved in developing their ability to use the chemical engineering discourse. Their strategy involved a number of interrelated aspects including interactive lectures where students were frequently given small problems to try on their own or discuss in groups; active tutorials where the class was randomly divided into groups of three students working on a set of problems; and a facility where tutors were on daily duty at specific times to support the work undertaken by the students - together with a space where the student could work either individually or in groups. To facilitate students' developing identities as engineers, a key project in this course involved them having an email conversation with a practising chemical engineer.

Given the diverse nature of their class, Case et al. (2007) found building a community within their class to be a particular challenge. In an attempt to address this situation, they ran a series of small group meetings during the first few weeks of the year where the lecturers could get to know the students group by group, and students could start to build peer networks. The afternoon tutorial sessions described above continued this process, and a peer mentoring scheme helped cement the relationships that were developing.

\section{Conclusion}

In this paper, we have presented a particular approach for improving student learning in engineering and included three vignettes of how some of the authors of this paper (from across three different institutions within South Africa) have gone about implementing this within their academic activities. Central to the argument is that we broaden our perspective on student learning. This includes recognising that in order for students to learn authentically and to participate in the classroom and associated workplace communities, they must master the dis courses of these communities and develop discursive identities that display membership of these communities. 


\section{References}

Ambrose, S.A. and Amon, C.H., 1997. Systematic design of a first-year mechanical engineering course at Carnegie-Mellon University. Journal of Engineering Education, 86 (2), 173-181.

Ausubel, D.P., 1968. Educational psychology: a cognitive view. New York: Holt.

Brown, D.E., 2000. Merging dynamics: an integrating perspective on learning, conceptual change, and teaching, and its implications for educational research. Paper presented at AERA annual meeting, 24-28 April 2000, New Orleans.

Brown, J.S., Collins, A., and Duguid, P., 1989. Situated cognition and the culture of learning. Educational Researcher, $18(1), 32-42$

Brown, B.A., Reveles, J.M., and Kelly, G.J., 2005. Scientific literacy and discursive identity: a theoretical framework for understanding science learning. Science Education, 89 (5), 779-802.

Case, J.M., Jawitz, J., and Ahmed, N., 2002. Smile nicely, make the tea - but will I ever be taken seriously? Engineering students' experiences of vacation work. In: J.M. Case, ed. Third Southern African conference on engineering education, October 2002, Durban, 12-16.

Case, J., Kotta, L., and Mogashana, D., 2007. Developing discursive identity and building community in first year chemical engineering. For Engineering and Science Educators, 11, 8-9.

Dahlgren, M.A., et al., 2006. From senior student to novice worker: learning trajectories in political science, psychology and mechanical engineering. Studies in Higher Education, 31 (5), 569-586.

Gee, J.P., 2001. Identity as an analytic lens for research in education. Review of Research in Education, 25 (1), 99-125.

Hanrahan, H., 2008. The Washington accord: history, development, status and trajectory. Paper presented at the 7th ASEE global colloquium on engineering education, 19-23 October 2008, Cape Town.

Hoit, M. and Ohland, M., 1998. The impact of a discipline-based introduction to engineering course on improving retention. Journal of Engineering Education, 87 (1), 79-85.

Holtman, L. and Marshall, D., 2008. Foundational provisions in the UWC Science Faculty: widening access and promoting success. In: L. Holtman, C. Julie, O. Mikalsen, and M. Ogunnyi, eds. Some developments in research in science and maths education in sub-Saharan Africa: access, adoption, adaptation and localization. Cape Town: Compress.

Jacobs, C., 2007. Towards a critical understanding of the teaching of discipline-specific academic literacies: making the tacit explicit. Journal of Education, 41, 59-82.

Jawitz, J. and Case, J., 1998. Exploring the reasons South African students give for studying engineering. International Journal of Engineering Education, 14 (4), 235-240.

Jawitz, J., Marais, N., and Hanrahan, H., 2001. Using accreditation to drive curriculum development in engineering. Australasian Journal of Engineering Education, 9 (2), 137-146.

Johnston, S., Lee, A., and Mcgregor, H., 1996. Engineering as captive discourse. Philosophy and Technology, 1, 3-4.

Jonassen, D., Strobel, J., and Lee, C.B., 2006. Everyday problem solving in engineering: lessons for engineering educators. Journal of Engineering Education, 95 (2), 139.

Lave, J. and Wenger, E., 1991. Situated learning: legitimate peripheral participation. Cambridge University Press: Cambridge, UK.

Lawless,A., 2005. Numbers and needs: addressing imbalances in the civil engineering profession. SouthAfrican Institution of Civil Engineering. Johannesburg, SA.

Lea, M.R. and Street, B.V., 2006. The 'Academic literacies' model: theory and applications. Theory into Practice, 45 (4), 368-377.

Lemke, J.L., 2001. Articulating communities: sociocultural perspectives on science education. Journal of Research in Science Teaching, 38 (3), 296-316.

Phipps, A., 2002. Engineering women: the 'gendering' of professional identities. International Journal of Engineering Education, 18 (4), 409-414.

Sfard, A., 1998. On two metaphors for learning and the dangers of choosing just one. Educational Researcher, 27 (2), 4-13.

Stonyer, H., 2001. The problem of women in engineering - is it women, engineering academics, curriculum or engineering - where to act? Australasian Journal of Engineering Education, 9 (2), 147-161.

Tate, E.D. and Linn, M.C., 2005. How does identity shape the experiences of women of color engineering students? Journal of Science Education and Technology, 14 (5), 483-493.

Walker, M., 2001. Engineering identities. British Journal of Sociology of Education, 22 (1), 75-89.

\section{About the authors}

Saalih Allie teaches in the Department of Physics at the University of Cape Town and is a principal member of the Physics Education Research group within the Department.

Mogamat Noor Armien is in the Department of Civil Engineering at the Cape Peninsula University of Technology.

Nicolette Burgoyne is completing a doctorate in Instructional Technology at Brigham Young University, with interests in complexity theory and collaborative learning. 
Jennifer Case teaches in the chemical engineering programme at the University of Cape Town and researches the student experience of learning.

Brandon Collier-Reed teaches in the Department of Mechanical Engineering and is the Director of the Centre for Research in Engineering Education (CREE) at the University of Cape Town.

Tracy Craig is a mathematics educator in the Academic Support Programme for Engineers in Cape Town (ASPECT) at the University of Cape Town, specialising in mathematics and the associated issues of identity and language.

Andrew Deacon works in the Centre for Educational Technology at the University of Cape Town. His research interests focus around the use of educational technology to support teaching and learning in universities.

Duncan Fraser holds degrees of $\mathrm{BSc}(\mathrm{ChemEng})$ and $\mathrm{PhD}$, both from the University of Cape Town, where he has been lecturing in chemical engineering since 1979.

Zulpha Geyer holds a bachelors degree in Social Anthropology and English Literature from the University of Cape Town and works at the Centre for Research in Engineering Education (CREE).

Cecilia Jacobs is the teaching and learning co-ordinator in the Engineering Faculty at the Cape Peninsula University of Technology. Her research interests are in disciplinary literacies, the way in which knowledge is structured in different disciplines, and how that knowledge is communicated through discipline-specific language.

Jeff Jawitz is a member of the Centre for Higher Education Development (CHED) at the University of Cape Town. Current areas of research include academic staff development, improving teaching and learning and the impact of race in higher education.

Bruce Kloot is an Academic Development Lecturer in the Department of Mechanical Engineering at the University of Cape Town. He is currently analysing South African higher education as a 'field' using Pierre Bourdieu's sociological framework.

Linda Kotta is an Academic Development Lecturer in the Department of Chemical Engineering at the University of Cape Town.

Genevieve Langdon teaches in the Department of Mechanical Engineering at the University of Cape Town and is originally from Liverpool in the UK. She has a PhD in the response of structures to gas explosions and an interest in engineering education.

Kate le Roux teaches mathematics and quantitative literacy at undergraduate level at the University of Cape Town.

Delia Marshall teaches in the Department of Physics at the University of the Western Cape. She currently coordinates an extended BSc degree for underprepared students entering university.

Disaapele Mogashana is an Academic Development Lecturer in the Academic Support Programme for Engineers in Cape Town (ASPECT) at the University of Cape Town.

Corrinne Shaw has drawn on multiple theoretical constructs for the design of learning contexts, including complexity and systems theory, in management education at the University of Cape Town.

Gillian Sheridan is a post-doctoral student in the Department of Chemical Engineering at the University of Cape Town.

Nicolette Wolmarans is an Academic Development Lecturer in the Department of Civil Engineering at the University of Cape Town. 